\title{
Evaluation of the efficacy and safety of inhaled magnesium sulphate in combination with standard treatment in patients with moderate or severe COVID- 19: A structured summary of a study protocol for a randomised controlled trial
}

Guitti Pourdowlat', Seyed Ruhollah Mousavinasab², Behrooz Farzanegan³, Alireza Kashefizadeh4, Zohreh Akhoundi Meybodi ${ }^{5}$, Maedeh Jafarzadeh ${ }^{1}$ and Shadi Baniasadi ${ }^{6^{*}}$ (D)

\begin{abstract}
Objectives: Basic and clinical studies have shown that magnesium sulphate ameliorates lung injury and controls asthma attacks by anti-inflammatory and bronchodilatory effects. Both intravenous and inhaled magnesium sulphate have a clinical impact on acute severe asthma by inhibition of airway smooth muscle contraction. Besides, magnesium sulphate can dilate constricted pulmonary arteries and reduce pulmonary artery resistance. However, it may affect systemic arteries when administered intravenously. A large number of patients with covid-19 admitted to the hospital suffer from pulmonary involvement. COVID-19 can cause hypoxia due to the involvement of the respiratory airways and parenchyma along with circulatory impairment, which induce ventilation-perfusion mismatch. This condition may result in hypoxemia and low arterial blood oxygen pressure and saturation presented with some degree of dyspnoea and shortness of breath. Inhaled magnesium sulphate as a smooth muscle relaxant (natural calcium antagonist) can cause both bronchodilator and consequently vasodilator effects (via a direct effect on alveolar arterioles in well-ventilated areas) in the respiratory tract. We aim to investigate if inhaled magnesium sulphate as adjuvant therapy to standard treatment can reduce ventilation-perfusion mismatch in the respiratory tract and subsequently improve arterial oxygen saturation in hospitalized patients with COVID-19.
\end{abstract}

Trial design: A multi-centre, open-label, randomised controlled trial $(\mathrm{RCT})$ with two parallel arms design (1:1 ratio) (Continued on next page)

\footnotetext{
* Correspondence: sbaniasadi@yahoo.com; baniasadi@sbmu.ac.ir

${ }^{6}$ Tracheal Diseases Research Centre, National Research Institute of

Tuberculosis and Lung Diseases (NRITLD), Shahid Beheshti University of Medical Sciences, Tehran, Iran

Full list of author information is available at the end of the article
}

(c) The Author(s). 2021 Open Access This article is licensed under a Creative Commons Attribution 4.0 International License, which permits use, sharing, adaptation, distribution and reproduction in any medium or format, as long as you give appropriate credit to the original author(s) and the source, provide a link to the Creative Commons licence, and indicate if changes were made. The images or other third party material in this article are included in the article's Creative Commons licence, unless indicated otherwise in a credit line to the material. If material is not included in the article's Creative Commons licence and your intended use is not permitted by statutory regulation or exceeds the permitted use, you will need to obtain permission directly from the copyright holder. To view a copy of this licence, visit http://creativecommons.org/licenses/by/4.0/. The Creative Commons Public Domain Dedication waiver (http://creativecommons.org/publicdomain/zero/1.0/) applies to the data made available in this article, unless otherwise stated in a credit line to the data. 
(Continued from previous page)

Participants: Patients aged 18-80 years hospitalized at Masih Daneshvari Hospital and Shahid Dr. Labbafinejad hospital in Tehran and Shahid Sadoughi Hospital in Yazd will be included if they meet the inclusion criteria of the study. Inclusion criteria are defined as 1. Confirmed diagnosis of SARS-CoV-2 infection based on polymerase chain reaction $(P C R)$ of nasopharyngeal secretions or clinical manifestations along with chest computed tomography (chest CT) scan 2. Presenting with moderate or severe COVID-19 lung involvement confirmed with chest CT scan and arterial oxygen saturation below 93\% 3. Length of hospital stay $\leq 48$ hours.

Patients with underlying cardiovascular diseases including congestive heart failure, bradyarrhythmia, heart block, the myocardial injury will be excluded from the study.

Intervention and comparator: Participants will be randomly divided into two arms. Patients in the intervention arm will be given both standard treatment for COVID-19 (according to the national guideline) and magnesium sulphate (5 cc of a $20 \%$ injectable vial or 2 cc of a $50 \%$ injectable vial will be diluted by 50 cc distilled water and nebulized via a mask) every eight hours for five days. Patients in the control (comparator) arm will only receive standard treatment for COVID-19.

Main outcomes: Improvement of respiratory function and symptoms including arterial blood oxygen saturation, dyspnoea (according to NYHA functional classification), and cough within the first five days of randomization.

Randomisation: Block randomisation will be used to allocate eligible patients to the study arms (in a 1:1 ratio). Computer software will be applied to randomly select the blocks.

Blinding (masking): The study is an open-label RCT without blinding.

Numbers to be randomised (sample size): The trial will be performed on 100 patients who will be randomly divided into two arms of control (50) and intervention (50).

Trial Status: The protocol is Version 5.0, January 05, 2021. Recruitment of the participants started on July 30, 2020, and it is anticipated to be completed by February 28, 2021.

Trial registration: The trial was registered in the Iranian Registry of Clinical Trials (IRCT) on July 28, 2020. It is available on https://en.irct.ir/trial/49879. The registration number is IRCT20191211045691N1.

Full protocol: The full protocol is attached as an additional file, accessible from the Trials website (Additional file 1). In the interest of expediting the dissemination of this material, the familiar formatting has been eliminated; this Letter serves as a summary of the key elements of the full protocol.

Keywords: COVID-19, hypoxia, inhalation, magnesium sulphate, protocol, randomised controlled trial, respiratory tract symptoms

\section{Supplementary Information}

The online version contains supplementary material available at https://doi. org/10.1186/s13063-021-05032-y.

Additional file 1.

\section{Acknowledgements}

We would like to express our gratitude to all the nurses and medical staff who participated in this trial and saved patients' lives during the COVID-19 pandemic.

\section{Authors' contributions}

Study design and protocol development: GP and SRM. Patients' recruitment and data collection: ZA, BF, MJ, and AK. Data analysis: SB. Data interpretation, manuscript writing, and submission: GP and SB. All authors approved the final manuscript before submission.

\section{Funding}

This trial has been funded by the National Research Institute of Tuberculosis and Lung Diseases, Tehran, Iran. We declare that the funding organisation has no role in the design of the study, and collection, analysis, interpretation of the data, and writing of the manuscript.
Availability of data and materials

We declare that the chief investigator and the corresponding author will have access to the final trial dataset. They will consider reasonable requests for data sharing. The requests can be sent to pourdowlat_g@yahoo.com.

\section{Ethics approval and consent to participate}

The current trial was approved by the Ethics Committee of the National Research Institute of Tuberculosis and Lung Diseases (NRITLD) on July 27, 2020. The ethics committee reference number is

IR.SBMU.NRITLD.REC.1399.148. We certify that this trial has received ethical approval from the appropriate ethical committee as described above. Informed consent will be obtained from all participants (or their legally authorized representatives) before participation in the trial.

Consent for publication

Not applicable.

\section{Competing interests}

There are no competing interests to be declared.

\section{Author details}

${ }^{1}$ Chronic Respiratory Diseases Research Centre, National Research Institute of Tuberculosis and Lung Diseases (NRITLD), Shahid Beheshti University of Medical Sciences, Tehran, Iran. ${ }^{2}$ Department of Clinical Pharmacy, Faculty of Pharmacy, Shiraz University of Medical Sciences, Shiraz, Iran. ${ }^{3}$ Critical Care Quality Improvement Research Centre, SBMU, Tehran, Iran. ${ }^{4}$ Shahid Dr. 
Labbafinejad Hospital, Shahid Beheshti University of Medical Sciences,

Tehran, Iran. ${ }^{5}$ Shahid Sadoughi University of Medical Sciences, Yazd, Iran.

${ }^{6}$ Tracheal Diseases Research Centre, National Research Institute of

Tuberculosis and Lung Diseases (NRITLD), Shahid Beheshti University of Medical Sciences, Tehran, Iran.

Received: 5 January 2021 Accepted: 7 January 2021

Published online: 18 January 2021

\section{Publisher's Note}

Springer Nature remains neutral with regard to jurisdictional claims in published maps and institutional affiliations.

Ready to submit your research? Choose BMC and benefit from:

- fast, convenient online submission

- thorough peer review by experienced researchers in your field

- rapid publication on acceptance

- support for research data, including large and complex data types

- gold Open Access which fosters wider collaboration and increased citations

- maximum visibility for your research: over $100 \mathrm{M}$ website views per year

At BMC, research is always in progress.

Learn more biomedcentral.com/submissions 